\title{
A theoretical investigation of human skin thermal response to near- infrared laser irradiation
}

Tianhong Dai, Brian M. Pikkula, Lihong V. Wang, Bahman Anvari

Tianhong Dai, Brian M. Pikkula, Lihong V. Wang, Bahman Anvari, "A theoretical investigation of human skin thermal response to near-infrared laser irradiation," Proc. SPIE 5312, Lasers in Surgery: Advanced Characterization, Therapeutics, and Systems XIV, (13 July 2004); doi: 10.1117/12.529146 


\title{
A theoretical investigation of human skin thermal response to near- infrared laser irradiation
}

\author{
Tianhong Dai ${ }^{\mathrm{a}}$, Brian M. Pikkula ${ }^{\mathrm{a}}$, Lihong V. Wang ${ }^{\mathrm{b}}$ and Bahman Anvari ${ }^{{ }^{\mathrm{a}}}$ \\ ${ }^{a}$ Department of Bioengineering, Rice University, Houston, TX, USA 77251; \\ ${ }^{b}$ Department of Biomedical Engineering, Texas A\&M University, College Station, TX, USA 77843
}

\begin{abstract}
Near-infrared wavelengths are absorbed less by epidermal melanin mainly located at the basal layer of epidermis (dermo-epidermal junction), and penetrate deeper into human skin dermis and blood than visible wavelengths. Therefore, laser irradiation using near-infrared wavelength may improve the therapeutic outcome of cutaneous hypervascular malformations in moderately to heavily pigmented skin patients and those with large-sized blood vessels or blood vessels extending deeply into the skin. A mathematical model composed of a Monte Carlo algorithm to estimate the distribution of absorbed light followed by numerical solution of a bio-heat diffusion equation was utilized to investigate the thermal response of human skin to near-infrared laser irradiation, and compared it with that to visible laser irradiation. Additionally, the effect of skin surface cooling on epidermal protection was theoretically investigated. Simulation results indicated that $940 \mathrm{~nm}$ wavelength is superior to 810 and $1064 \mathrm{~nm}$ in terms of the ratio of light absorption by targeted blood vessel to the absorption by the basal layer of epidermis, and is more efficient than $595 \mathrm{~nm}$ wavelength for the treatment of patients with large-sized blood vessels and moderately to heavily pigmented skin. Dermal blood content has a considerable effect on the laser-induced peak temperature at the basal layer of epidermis, while the effect of blood vessel size is minimum.
\end{abstract}

Keywords: Cutaneous hyper-vascular malformations, laser therapy, blood vessel coagulation, epidermal protection

\section{INTRDUCTION}

Pulsed dye lasers at the wavelengths of 585 and $595 \mathrm{~nm}$ have been the common choices for the treatment of cutaneous hyper-vascular malformations such as telangiectasia ${ }^{1}$, port wine $\operatorname{stain}^{2-5}$ and hemangiomas ${ }^{6}$. However, clinical studies have shown that complete blanching of the lesions is not commonly achieved, and multiple treatments are usually required to obtain optimal blanching ${ }^{2-6}$. Moreover, in some cases, patients are unresponsive to pulsed dye laser irradiation $^{7}$. The possible reasons for these limited therapeutic outcomes are the limited light penetration depth in largesized blood vessels as well as blood vessels extending deeply into the skin dermis, and subsequently non-uniform heating in various blood vessel layers. Additionally, as epidermal melanin, mainly located at the basal layer of epidermis (dermo-epidermal junction), competes with subsurface targeted blood vessels in the absorption of laser light, a large number of the patients, namely those with high melanin concentration skin types, are still excluded from the laser treatment due to significant light absorption by the epidermal melanin, which can lead to persistent hyper-pigmentation, textural changes to the skin ${ }^{8}$.

Near-infrared wavelengths are absorbed less by epidermal melanin, and penetrate deeper into skin dermis and blood than visible wavelengths. Therefore, laser irradiation using near-infrared wavelength may improve the therapeutic outcome of cutaneous hyper-vascular malformations in moderately to heavily pigmented skin patients and those with large-sized blood vessels or blood vessels extending deeply into the skin. Using a mathematical model composed of a Monte Carlo algorithm to estimate the distribution of absorbed light followed by numerical solution of a bio-heat diffusion equation, we investigated the thermal response of human skin to near-infrared wavelength laser irradiation, and evaluated the feasibility of near-infrared laser for the treatment of cutaneous hyper-vascular lesions.

*anvari@rice.edu; phone 1713 348-5870; fax 1713 348-5877; ruf.rice.edu/ banvari 


\section{METHODOLOGY}

\subsection{Human skin geometry}

The geometry to simulate human skin with cutaneous hyper-vascular malformations consisted of a $60 \mu \mathrm{m}$ thick epidermis with a $15 \mu \mathrm{m}$ thick basal melanin layer, and a $1940 \mu \mathrm{m}$ thick dermis embedded with discrete ecstatic blood vessels (Fig. 1). The volume fractions of melanosomes in the basal layer of epidermis were assumed to be 15, 50, and $95 \%$ (corresponding to the average volume fractions of 3.8, 12.5, and $23.8 \%$ based on the whole epidermis) for lightly, moderately, and heavily pigmented skin, respectively, based on the data reported in the literature ${ }^{9}$. The blood vessels were assumed to be straight cylinders running parallel to $y$ direction and with infinite lengths. The number of blood vessels and their sizes could be varied. The haematocrit $(h c t)$ of the whole blood was $45 \%$. The beam spot was assumed to be a square flat-top profile with a size of $5 \mathrm{~mm} \times 5 \mathrm{~mm}$.

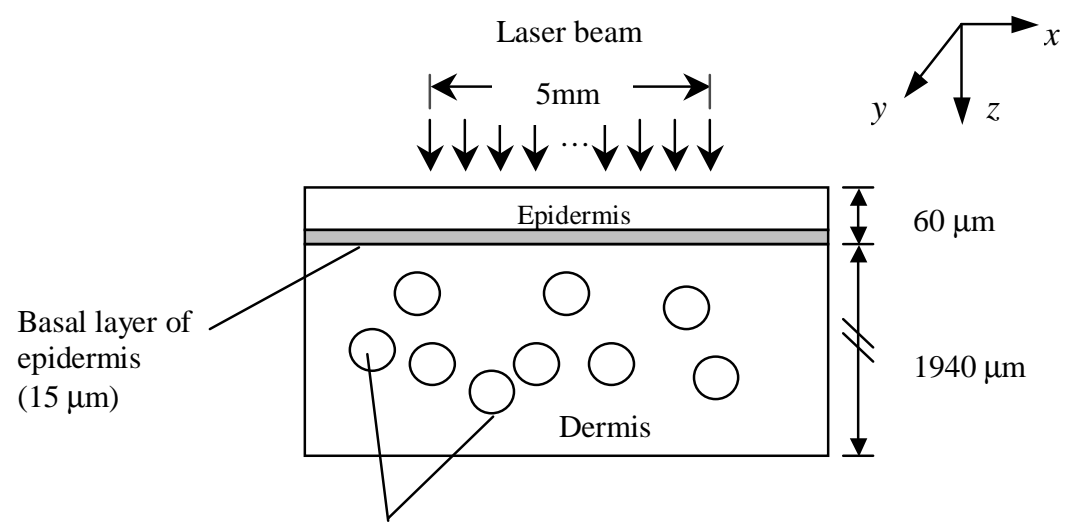

Ectatic blood vessels

Figure 1: Geometry model of human skin with cutaneous hyper-vascular malformation.

\subsection{Optical properties of human skin}

In the present study, three near-infrared wavelengths 810, 940 and $1064 \mathrm{~nm}$, and two visible wavelengths 585 and 595 $\mathrm{nm}$ were investigated. The determination of skin optical properties at various wavelengths is detailed as follows.

\subsubsection{Optical properties of blood}

The absorption coefficients of blood $\mu_{\mathrm{a}, \mathrm{blood}}$ at 810,940 , and $1064 \mathrm{~nm}$ were converted from the extinction coefficients for hemoglobin ${ }^{10}$. The original data in units of $\mathrm{mM}^{-1} \mathrm{~cm}^{-1}$ were multiplied by a factor of 5.4 to obtain the absorption coefficient of whole blood with $h c t=45 \%$ in units of $\mathrm{cm}^{-1} 9$. The absorption coefficients of blood at 585 and $595 \mathrm{~nm}$ for $h c t=45 \%$ were scaled from the data reported by Kienle $e t a l$, which was for $h c t=40 \%$ originally ${ }^{11}$.

The reduced scattering coefficient of blood $\mu_{\mathrm{s}, \text { blood }}^{\prime}$ at $810 \mathrm{~nm}$ was reported by Roggan et al ${ }^{12}$ as $6.6 \mathrm{~cm}^{-1}$ and $3.9 \mathrm{~cm}^{-1}$ for $40 \%$ hct. Thus, the mean value of $\left.\mu_{\mathrm{s}, \mathrm{blood}}^{\prime}\right|_{h c t=40 \%}=5.25 \mathrm{~cm}^{-1}$ was applied to $810 \mu \mathrm{m}$ wavelength for $40 \%$ hct. We assumed the corresponding anisotropy factor $g$ to be 0.99 , and then the scattering coefficient of blood at $810 \mathrm{~nm}$ wavelength for $h c t=40 \%$ was:

$$
\left.\mu_{\mathrm{s}, \text { blood }}\right|_{h c t=40 \%}=\left.\mu_{\mathrm{s}, \text { blood }}^{\prime}\right|_{c t=40 \%} /(1-\mathrm{g})=525.00 \mathrm{~cm}^{-1} .
$$

A previous study ${ }^{13}$ indicated that, scattering and absorption increase linearly with hct if $h c t<50 \%$. As a result, for $h c t=45 \%$, scattering coefficient of blood at $810 \mathrm{~nm}$ wavelength was:

$$
\left.\mu_{\mathrm{s}, \text { blood }}\right|_{h c t=45 \%}=\left.\mu_{\mathrm{s}, \text { blood }}\right|_{h c t=40 \%} \times(45 / 40)=590.62 \mathrm{~cm}^{-1} \text {. }
$$

The scattering coefficients at 940 and $1064 \mathrm{~nm}$ wavelengths were derived from the relationship ${ }^{13}$ that the scattering coefficient decreases for wavelength above $800 \mathrm{~nm}$ with approximately $\lambda^{-1.7}$, where $\lambda$ is the wavelength, and the scattering coefficient at $810 \mathrm{~nm}$ served as the reference value. The anisotropy factors $g$ were set to be 0.99 as well for the other two near-infrared wavelengths 940 and $1064 \mathrm{~nm}^{14}$, and 0.995 for the visible wavelengths 585 and $595 \mathrm{~nm}^{11}$. 


\subsubsection{Optical properties of skin epidermis}

Based on the model geometry used in the present study, skin epidermis is composed of two layers: a melaninless epidermis layer and basal melanin-filled layer. The absorption coefficient of melaninless epidermis $\mu_{\mathrm{a}, \mathrm{epi}}\left(\mathrm{cm}^{-1}\right)$ was given by ${ }^{9}$ :

$$
\mu_{\mathrm{a}, \mathrm{epi}}=\mu_{\mathrm{a}, \mathrm{base}}=0.244+85.3 \exp [-(\lambda-154) / 66.2]
$$

where, $\mu_{\mathrm{a} \text {,base }}$ is the baseline absorption coefficient of skin (i.e., absorption coefficient of melaninless epidermis or bloodless dermis) ${ }^{9}$.

The total optical absorption coefficient of the basal layer of epidermis $\mu_{\mathrm{a} \text {, ebas }}$ depends on a minor baseline skin absorption and a dominant melanin absorption due to the melanosomes in the basal layer:

$$
\mu_{\mathrm{a}, \mathrm{ebas}}=f_{\mathrm{mel}} \cdot \mu_{\mathrm{a} \text {,mel }}+\left(1-f_{\mathrm{mel}}\right) \mu_{\mathrm{a} \text {, base }}
$$

where $f_{\text {mel }}$ is the volume fraction of melanosomes in the basal layer of epidermis; $\mu_{\mathrm{a}, \mathrm{mel}}\left(\mathrm{cm}^{-1}\right)$ is the absorption coefficient of a single melanosome, and was calculated by ${ }^{9}$ :

$$
\mu_{\mathrm{a}, \mathrm{mel}}=6.6 \times 10^{11} \cdot \lambda^{-3.33}
$$

Scattering coefficients of melaninless epidermis and basal layer of epidermis were approximated to be the same, and were calculated by ${ }^{9}$ :

$$
\mu_{\mathrm{s}}=\left(2 \times 10^{5} \cdot \lambda+2 \times 10^{12} \cdot \lambda\right) /(1-g)
$$

where $\mu_{\mathrm{s}}$ is the scattering coefficient $\left(\mathrm{cm}^{-1}\right)$. Values of $g$ were assumed to be 0.91 for the near-infrared wavelengths 810 , 940 , and $1064 \mathrm{~nm}^{14}$, and 0.8 for visible wavelengths 585 and $595 \mathrm{~nm}^{11}$.

\subsubsection{Optical properties of skin dermis}

Absorption coefficient of dermis $\mu_{\mathrm{a}, \mathrm{der}}$ is expressed as

$$
\mu_{\mathrm{a}, \text { der }}=f_{\text {blood }} \mu_{\mathrm{a} \text {,blood }}+\left(1-f_{\text {blood }}\right) \mu_{\text {a,base }}
$$

where $f_{\text {blood }}$ is the volume fraction of blood in the dermis (the blood content of ecstatic blood vessels is not taken into account here). A typical value of $f_{\text {blood }}$ is $0.2 \%$ where a homogeneous distribution of blood in the dermis is assumed ${ }^{9}$. Scattering coefficient and anisotropy factor of the dermis were considered to be the same as those of epidermis.

In summary, the optical properties used in the present study are depicted in Table 1.

Table 1: Human skin optical properties used in the present study

\begin{tabular}{cccccccc}
\hline $\begin{array}{c}\text { Wavelength } \\
(\mathrm{nm})\end{array}$ & $\begin{array}{c}\text { Optical } \\
\text { properties }\end{array}$ & Epidermis & $\begin{array}{c}\text { Basal layer } \\
(\mathrm{L})^{*}\end{array}$ & $\begin{array}{c}\text { Basal layer } \\
(\mathrm{M}) *\end{array}$ & $\begin{array}{c}\text { Basal layer } \\
(\mathrm{H}) *\end{array}$ & Dermis & Blood \\
\hline \multirow{3}{*}{810} & $\mu_{\mathrm{a}}\left(\mathrm{cm}^{-1}\right)$ & 0.2482 & 20.65 & 68.24 & 129.44 & 0.2576 & 4.935 \\
& $\mu_{\mathrm{s}}\left(\mathrm{cm}^{-1}\right)$ & 148.02 & 148.02 & 148.02 & 148.02 & 148.02 & 590.62 \\
& $g$ & 0.91 & 0.91 & 0.91 & 0.91 & 0.91 & 0.99 \\
\hline \multirow{5}{*}{940} & $\mu_{\mathrm{a}}\left(\mathrm{cm}^{-1}\right)$ & 0.2446 & 12.66 & 41.62 & 78.85 & 0.2577 & 6.791 \\
& $\mu_{\mathrm{s}}\left(\mathrm{cm}^{-1}\right)$ & 105.57 & 105.57 & 105.57 & 105.57 & 105.57 & 458.58 \\
& $g$ & 0.91 & 0.91 & 0.91 & 0.91 & 0.91 & 0.99 \\
\hline \multirow{5}{*}{1064} & $\mu_{\mathrm{a}}\left(\mathrm{cm}^{-1}\right)$ & 0.2441 & 8.45 & 27.59 & 52.20 & 0.2501 & 3.23 \\
& $\mu_{\mathrm{s}}\left(\mathrm{cm}^{-1}\right)$ & 81.37 & 81.37 & 81.37 & 81.37 & 81.37 & 371.48 \\
& $g$ & 0.91 & 0.91 & 0.91 & 0.91 & 0.91 & 0.99 \\
\hline \multirow{2}{*}{595} & $\mu_{\mathrm{a}}\left(\mathrm{cm}^{-1}\right)$ & 0.3531 & 57.38 & 190.45 & 361.53 & 0.4492 & 48.4 \\
& $\mu_{\mathrm{s}}\left(\mathrm{cm}^{-1}\right)$ & 148.69 & 148.69 & 148.69 & 148.69 & 148.69 & 523.12 \\
& $g$ & 0.8 & 0.8 & 0.8 & 0.8 & 0.8 & 0.995 \\
\hline \multirow{2}{*}{585} & $\mu_{\mathrm{a}}\left(\mathrm{cm}^{-1}\right)$ & 0.3709 & 60.71 & 201.50 & 382.52 & 0.8 & 214.9 \\
& $\mu_{\mathrm{s}}\left(\mathrm{cm}^{-1}\right)$ & 156.06 & 156.06 & 156.06 & 156.06 & 156.06 & 525.38 \\
& $g$ & 0.8 & 0.8 & 0.8 & 0.8 & 0.8 & 0.995 \\
\hline
\end{tabular}

* L: light pigmentation, M: moderate pigmentation, $\mathrm{H}$ : heavy pigmentation

\subsection{Mathematical model}

Mathematical model consisted of a Monte Carlo algorithm ${ }^{15}$ to calculate the distribution of absorbed light in the skin; and a bio-heat conduction model to calculate the transient temperature distribution. Each simulation was carried out for 
$1,000,000$ photons. The initial skin temperature was assumed to be $33{ }^{\circ} \mathrm{C}$. The effect of cryogen (R134A) spray cooling was also incorporated in the model (Table 2) ${ }^{16}$.

Table 2: Boundary conditions of bio-heat conduction model ${ }^{16}$

\begin{tabular}{ccc}
\hline Time period & $\begin{array}{c}\text { Heat transfer coefficient } \\
\left(\mathrm{W} / \mathrm{m}^{2}{ }^{\circ} \mathrm{C}\right)\end{array}$ & $\begin{array}{c}\text { Temperature of the medium * right } \\
\text { above the skin surface }\left({ }^{\circ} \mathrm{C}\right)\end{array}$ \\
\hline Spurt application & 4,000 & -50 \\
Cryogen pool residence & 3,000 & -26 \\
Rewarming & 10 & 25 \\
\hline The medium refers to cryogen film during the spurt duration and cryogen pool residence, and refers to air \\
during the rewarming period.
\end{tabular}

The thermo-physical properties of skin used in the study were density $\rho=1,200 \mathrm{~kg} / \mathrm{m}^{3}$, specific heat capacity $C=3,600$ $\mathrm{J} /\left(\mathrm{kg}{ }^{\circ} \mathrm{C}\right)$, thermal conductivities $k=0.26,0.53,0.53 \mathrm{~W} /\left(\mathrm{m}{ }^{\circ} \mathrm{C}\right)$ for epidermis, dermis, and blood, respectively ${ }^{17}$. Additionally, a damage integral based on Arrhenius relationship ${ }^{18}$ was used to estimate the thermal damage to the skin. The coefficients used in the damage integral for bulk skin were ${ }^{19}$ : molecular collision frequency factor $A=1.8 \times 10^{51} \mathrm{~s}^{-1}$ and damage process activation energy $E=327,000 \mathrm{~J} / \mathrm{mol}$. When the damage integral reaches $1,63 \%$ of the tissue is assumed to be damaged. This limit was taken to be the criteria for irreversible damage. The outputs of the model were the temperature profiles and coagulated area maps within the skin.

\section{RESULTS}

\subsection{Verification of human skin optical properties}

In order to verify the validity of the human skin optical properties used in the present theoretical study (calculated by the formulas in Section 2.2, depicted in Table 1), we compared the simulation results of threshold incident dosages for epidermal damage in response to $595 \mathrm{~nm}$ laser irradiation (Table 3a) with the experimental results of an in-vivo study of normal human skin irradiated at the same wavelength (Table 3b). The in-vivo study was conducted by our group. The laser pulse duration was $1.5 \mathrm{~ms}$, and cryogen spurt duration $100 \mathrm{~ms}$. For normal human skin, the blood content of the dermis was assumed to be $0.2 \%$ in the simulation ${ }^{9}$.

Table 3a: Simulation results of threshold incident dosages for epidermal damage in response to 595 nm laser irradiation in conjunction with a $100 \mathrm{~ms}$ cryogen spurt. Laser pulse duration: $1.5 \mathrm{~ms}$.

\begin{tabular}{cccc}
\hline Skin pigmentation & $f_{\text {mel }}(\%)$ & $f_{\text {mel }}^{\prime}(\%)$ & $D_{\text {th }}\left(\mathrm{J} / \mathrm{cm}^{2}\right)$ \\
\hline Light & 15 & 3.8 & 33 \\
Moderate & 50 & 12.5 & 16.8 \\
Heavy & 95 & 23.8 & 12.7 \\
\hline
\end{tabular}

$f_{\text {mel }}$ : Volume fraction of melanosomes based on the basal layer of epidermis;

$f^{\prime}{ }_{\text {mel }}$ : Volume fraction of melanosomes based on the whole epidermis;

$D_{\text {th }}$ : Threshold incident dosage for epidermal damage.

Table $3 b^{\star}:$ In-vivo experimental results of threshold incident dosages for epidermal damage in response to $595 \mathrm{~nm}$ laser irradiation in conjunction with a $100 \mathrm{~ms}$ cryogen spurt. Laser pulse duration: $1.5 \mathrm{~ms}$.

\begin{tabular}{|c|c|c|c|}
\hline Sample \# & Skin type $^{+}$ & $D_{\mathrm{th}}\left(\mathrm{J} / \mathrm{cm}^{2}\right)$ & $D_{\text {th, av }}\left(\mathrm{J} / \mathrm{cm}^{2}\right)$ \\
\hline 1 & II & $>30^{*}$ & \\
\hline 2 & II & $>30 *$ & $>30$ \\
\hline 3 & II & 30 & \\
\hline 4 & III & 12 & \\
\hline 5 & III & 22 & 20.7 \\
\hline 6 & III & 28 & \\
\hline 7 & $\mathrm{~V}$ & 8 & \\
\hline 8 & $\mathrm{~V}$ & 14 & 9 \\
\hline 9 & $\mathrm{~V}$ & 5 & \\
\hline \multicolumn{4}{|c|}{$\begin{array}{l}\text { Unpublished data of an in-vivo study conducted in our group; } \\
+ \text { Fitzpatric skin classification }{ }^{20} \text {; } \\
D_{\text {th, av }} \text { : Average threshold incident dosage for epidermal damage; }\end{array}$} \\
\hline
\end{tabular}


Normally, Fitzpatric skin types I-II, III-IV, and V-VI are considered respectively as lightly, moderately, and heavily pigmented skin types ${ }^{21}$. For lightly pigmented skin, only type II was obtained in the in-vivo experiments (Table $3 b$ ), and the average value of the threshold incident dosage $D_{\mathrm{th}}$, av was higher than $30 \mathrm{~J} / \mathrm{cm}^{2}$; the corresponding predicted threshold incident dosage for lightly pigmented skin was $33 \mathrm{~J} / \mathrm{cm}^{2}$. For moderately pigmented skin, the experimental and simulation results were 20.7 and $16.8 \mathrm{~J} / \mathrm{cm}^{2}$, respectively. Considering the experimental result was only from type III skin and no type IV skin (for which the value is expected to be lower), the prediction can be considered to be reasonable. For heavily pigmented skin, the predicted value $\left(12.7 \mathrm{~J} / \mathrm{cm}^{2}\right)$ is $41 \%$ higher than the experimental result $\left(9 \mathrm{~J} / \mathrm{cm}^{2}\right)$. One of the possible reasons for this discrepancy is the large range of the melanin concentration in heavily pigmented skin: 18$43 \%$ based on the whole epidermis (Table 4 ).

Table 4: Reported data of volume fraction of melanosomes based on the whole epidermis in different skin types ${ }^{9}$

\begin{tabular}{ccc}
\hline Skin pigmentation & $f^{\prime}{ }_{\text {mel }}(\%)$ & $f^{\prime}{ }_{\text {mel av }}(\%)$ \\
\hline Light & $1.3-6.3$ & 3.8 \\
Moderate & $11-16$ & 13.5 \\
Heavy & $18-43$ & 30.5 \\
\hline$f^{\prime}$ & &
\end{tabular}

\subsection{Ratios of light absorptions by dermal blood vessel to the basal layer of epidermis}

Fig. 2 shows the one-dimensional simulation results of the ratios of light absorptions (absorbed light energy) by dermal blood vessel versus the basal layer of epidermis at three different commercially available near-infrared wavelengths: 810, 940, and $1064 \mathrm{~nm}$. The values of the light absorptions were the integrals over the whole blood vessel depth and epidermal basal layer depth, respectively. The blood vessel thickness was $800 \mu \mathrm{m}$ (representing a large-sized blood vessel) and was located $200 \mu \mathrm{m}$ deep from the skin surface. Moderate pigmentation was assumed here. It can be seen from Fig. 2 that $940 \mathrm{~nm}$ wavelength is superior to 810 and $1064 \mathrm{~nm}$ in terms of the ratio of light absorption by dermal blood vessel versus the basal layer of epidermis. Consistent results were also obtained when varying blood vessel thickness and location depth, as well as skin pigmentation. Based on the result above, the present study mainly focused on $940 \mathrm{~nm}$ wavelength.

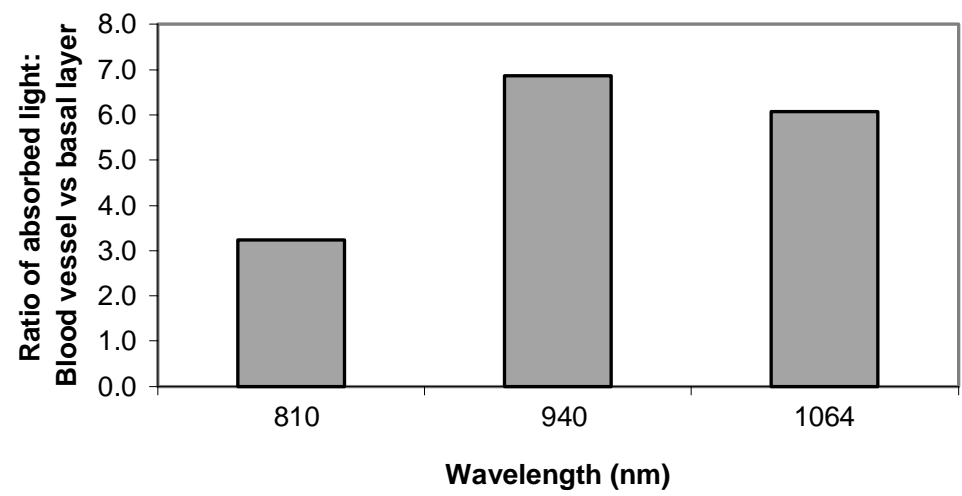

Figure 2: Ratios of absorbed light by blood vessel to the basal layer of epidermis at 810,940 , and 1064 nm wavelengths.

\subsection{Light absorption distributions}

Fig. 3 illustrates the distributions of absorbed light as a function of skin depth at various wavelengths 585, 595, and 940 $\mathrm{nm}$. All data in Fig.3 were normalized to the peak value at the basal layer of epidermis in response to $585 \mathrm{~nm}$ irradiation. The blood vessel thickness was $800 \mu \mathrm{m}$ and located $200 \mu \mathrm{m}$ deep from the skin surface. First, it can be seen that the peak values of light absorption by the basal layer of epidermis at 585 and $595 \mathrm{~nm}$ wavelengths are almost 5 times higher than that at $940 \mathrm{~nm}$. Second, unlike the pronounced gradient of absorbed light distribution in blood vessel at 585 and 595 $\mathrm{nm}$ wavelengths, the light distribution at $940 \mathrm{~nm}$ is approximately uniform. Third, optical selectivity can still be achieved at $940 \mathrm{~nm}$ wavelength, as the light absorption by blood at $940 \mathrm{~nm}$ is higher than that by the surrounding dermis. 


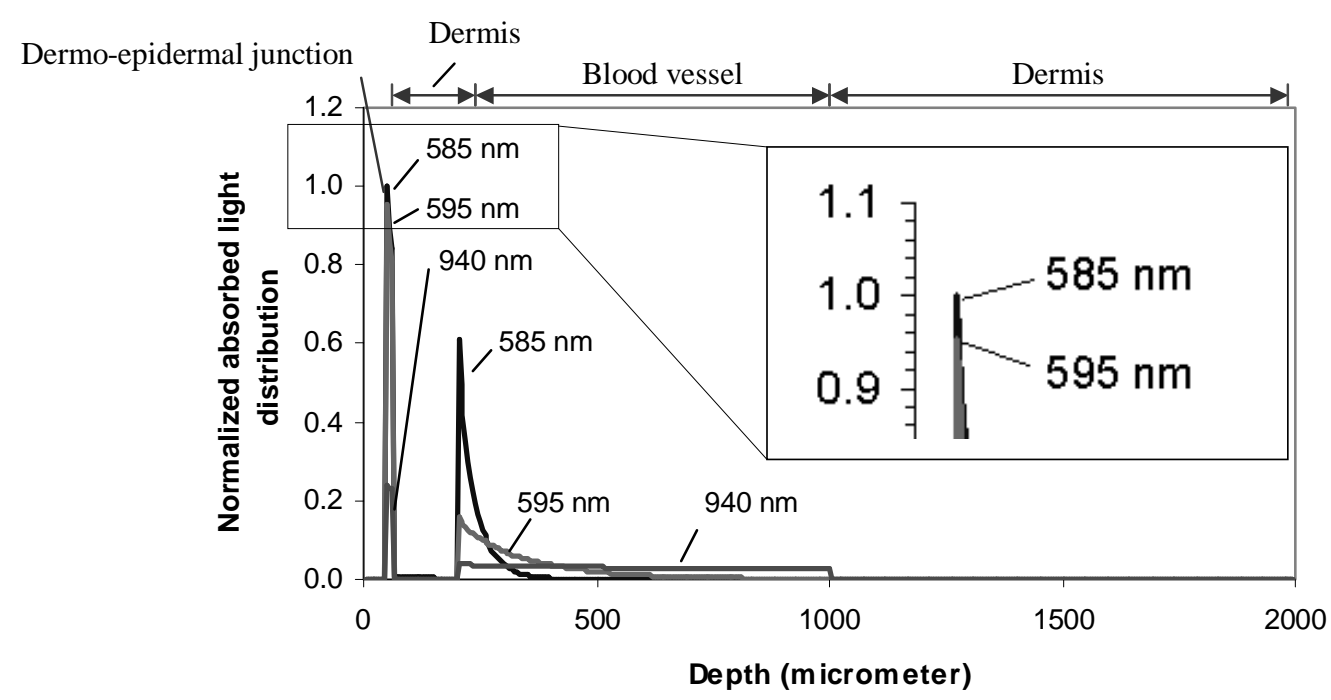

Figure 3: Predicted distribution of absorbed light in skin at the wavelengths of 585, 595, and 940nm.

\subsection{Blood vessels coagulation}

\subsubsection{Lightly pigmented skin}

Shown in Fig.4 are the simulation results of laser-induced dermal blood vessel photocoagulation maps in lightly pigmented skin irradiated by 595 and $940 \mathrm{~nm}$ wavelengths at the threshold incident dosages $D_{\text {th }}^{\prime}$ (The dark areas indicate the coagulated areas in the skin), where $D_{\text {th }}^{\prime}$ is defined as the highest value of the incident dosage that does not cause epidermal damage or perivascular tissue damage. Value of $D_{\text {th }}^{\prime}$ is dependent on laser wavelength, laser pulse duration, cryogen spurt duration, and skin pigmentation level. Cryogen spurt duration was $100 \mathrm{~ms}$ and the blood vessel sizes were $500 \mu \mathrm{m}$ in diameter. When the laser pulse duration was $1.5 \mathrm{~ms}$, no blood vessel coagulation occurred when irradiate at $595 \mathrm{~nm}$ wavelength (Fig. 4a), while one blood vessel was completely coagulated and the other considerably coagulated at $940 \mathrm{~nm}$ wavelength (Fig. 4e). When the laser pulse duration was increased to 40 and $100 \mathrm{~ms}$, blood vessels were considerably coagulated at $595 \mathrm{~nm}$ (Fig. 4b, c) and completely coagulated at $940 \mathrm{~nm}$ (Fig. 4f, g).
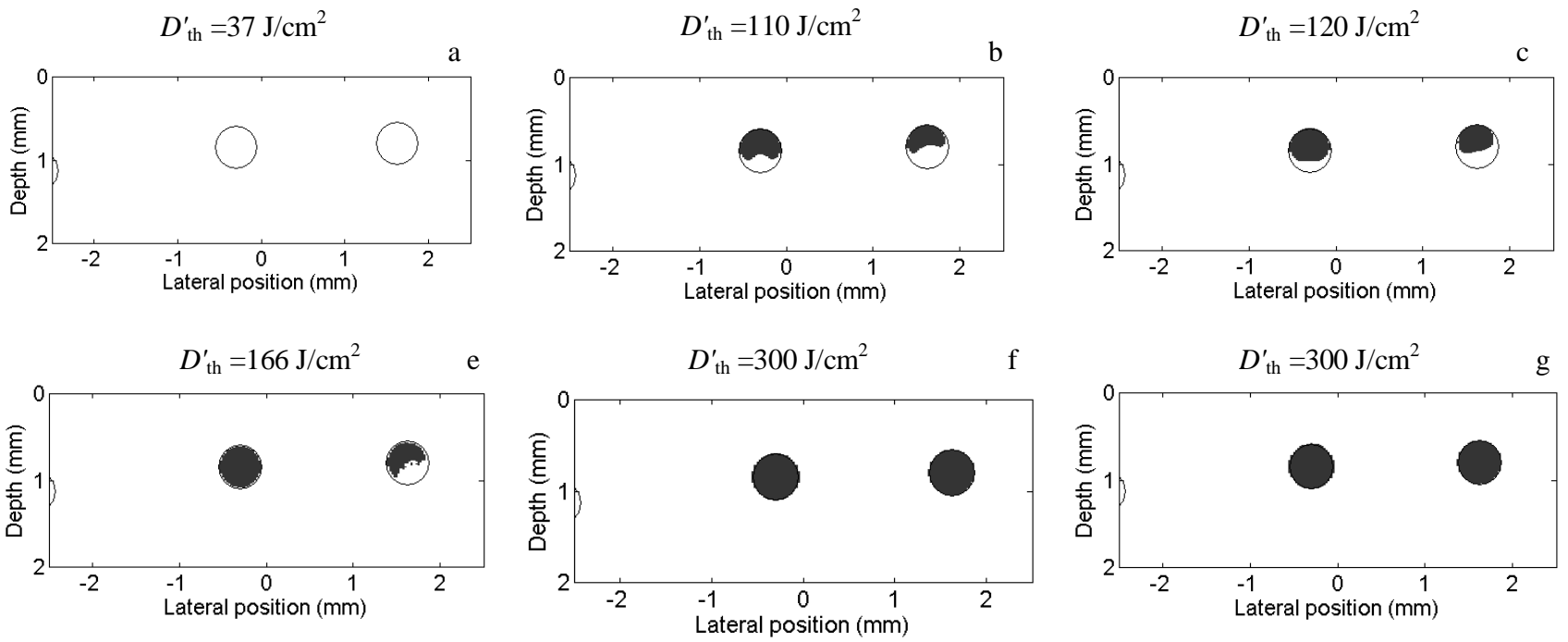

Figure 4: Comparison of blood vessel coagulation in response to 595 (a, b, c) and $940 \mathrm{~nm}(\mathrm{e}, \mathrm{f}, \mathrm{g})$ irradiations in lightly pigmented skin at the threshold incident dosages $D_{\text {th }}^{\prime}$. Cryogen spurt duration: $100 \mathrm{~ms}$. Laser pulse durations: 1.5 (a, e), 40 (b, f), and $100 \mathrm{~ms}$ (c, g). Circled areas: blood vessels; Dark areas: coagulated areas of blood vessels. 


\subsubsection{Moderately pigmented skin}

The corresponding simulation results for moderately pigmented skin are given in Fig. 5. When irradiated at $595 \mathrm{~nm}$ wavelength, no blood vessel coagulation occurred at all laser pulse durations from 1.5-100 ms (Fig. 5a, b, c). While at $940 \mathrm{~nm}$, almost complete blood coagulation was predicted when laser pulse duration reached $100 \mathrm{~ms}$ (Fig. 5f).
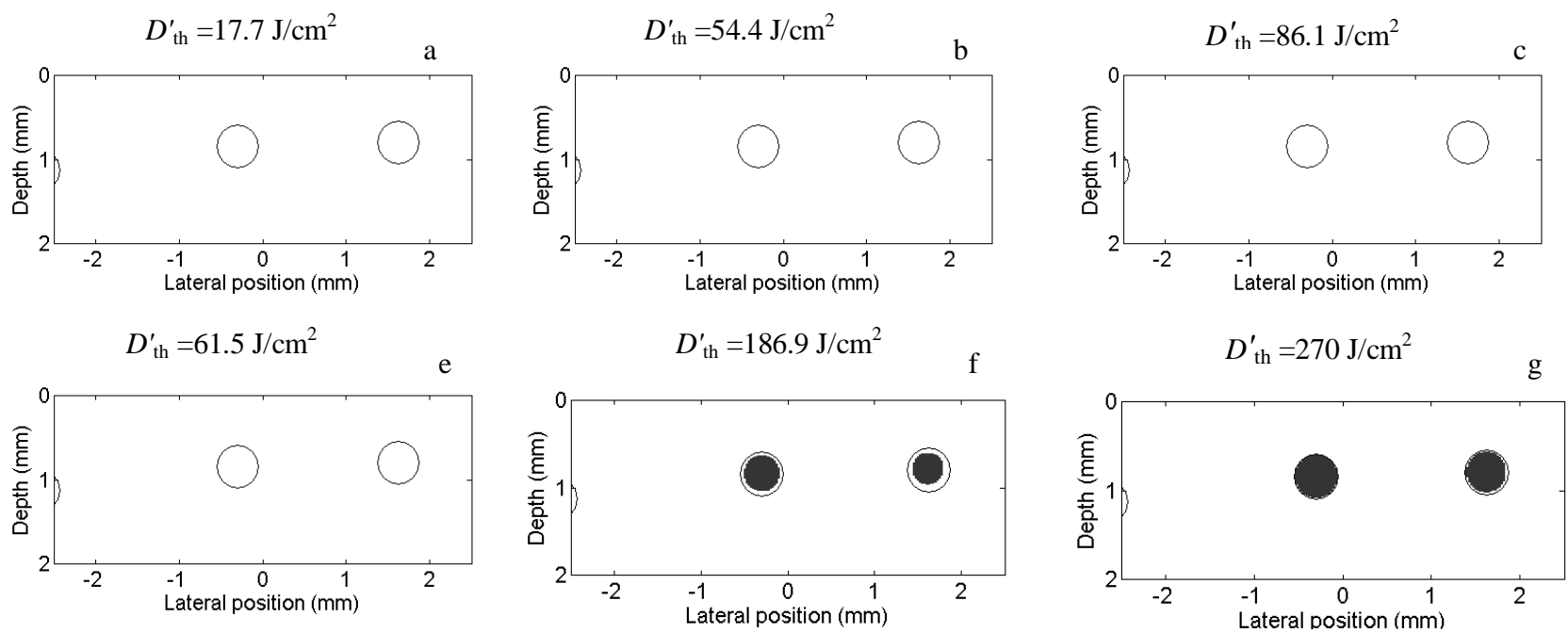

Figure 5: Comparison of blood vessel coagulation in response to 595 (a, b, c) and $940 \mathrm{~nm}(\mathrm{e}, \mathrm{f}, \mathrm{g})$ irradiations in moderately pigmented skin at the threshold incident dosages $D_{\text {th }}^{\prime}$. Cryogen spurt duration: $100 \mathrm{~ms}$. Laser pulse durations: 1.5 (a, e), 40 (b, f), and $100 \mathrm{~ms}$ (c, g). Circled areas: blood vessels; Dark areas: coagulated areas of blood vessels.

\subsubsection{Heavily pigmented skin}

In heavily pigmented skin, blood vessel coagulation did not occur in response to $595 \mathrm{~nm}$ irradiations regardless of the pulse durations from 1.5-100 ms when the corresponding threshold incident dosages $D_{\text {th }}^{\prime}$ were applied (Fig.6a, b, c). At $940 \mathrm{~nm}$, only little blood vessel coagulation was predicted when the pulse duration was $100 \mathrm{~ms}$ (Fig. 6g). However, when the laser pulse duration was further increased to $200 \mathrm{~ms}$, and cryogen spurt duration to $200 \mathrm{~ms}$, blood vessels were almost fully coagulated when irradiated at $940 \mathrm{~nm}$ (Fig. 7b). In the meantime, still no coagulation was predicted at 595 $\mathrm{nm}$ under the same conditions (Fig. 7a).
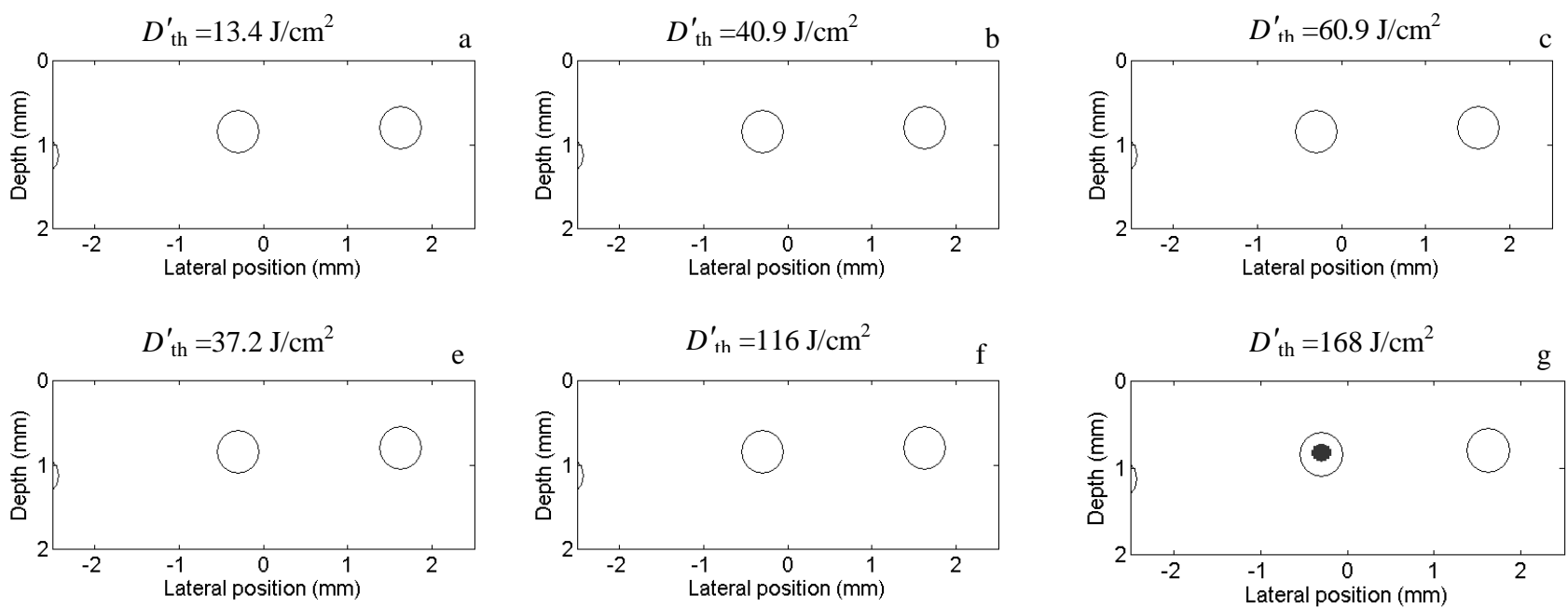

Figure 6: Comparison of blood vessel coagulation in response to 595 (a, b, c) and $940 \mathrm{~nm}$ (d, e, f) irradiations in heavily pigmented skin at the threshold incident $D_{\text {th. }}^{\prime}$ Cryogen spurt duration: $100 \mathrm{~ms}$. Laser pulse durations: 1.5 (a, e), 40 (b, f), and $100 \mathrm{~ms}$ (c, g). Circled areas: blood vessels; Dark areas: coagulated areas of blood vessels. 


$$
D_{\mathrm{th}}^{\prime}=96 \mathrm{~J} / \mathrm{cm}^{2}
$$

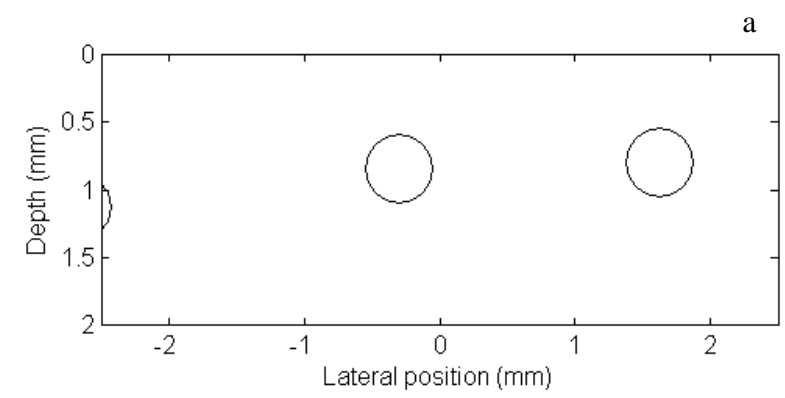

$D_{\text {th }}^{\prime}=260 \mathrm{~J} / \mathrm{cm}^{2}$

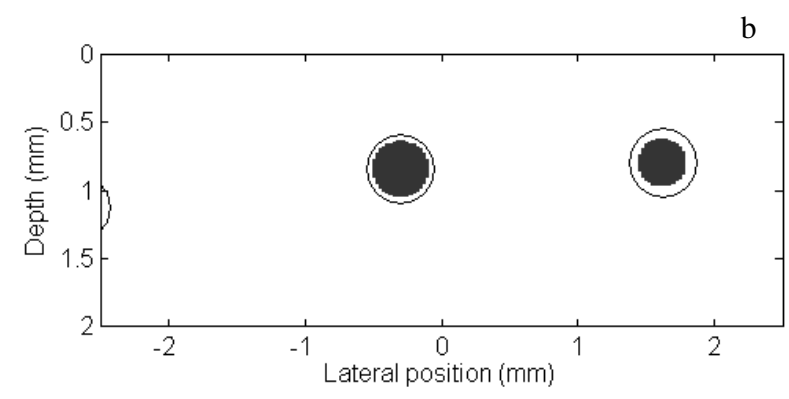

Figure 7: Comparison of blood vessel coagulation in response to (a) 595 and (b) $940 \mathrm{~nm}$ irradiations in heavily pigmented skin at the threshold incident dosages $D_{\text {th. }}^{\prime}$. Cryogen spurt duration: $200 \mathrm{~ms}$. Laser pulse duration: $200 \mathrm{~ms}$. Circled areas: blood vessels; Dark areas: coagulated areas of blood vessels.

\subsection{Effect of dermal blood content}

The simulation results for the effect of dermal blood content on the laser-induced peak temperature at the basal layer of epidermis are presented in Fig. 8a. The irradiation wavelength $\lambda=940 \mathrm{~nm}$, incident dosage $D_{0}=100 \mathrm{~J} / \mathrm{cm}^{2}$, cryogen spurt duration $100 \mathrm{~ms}$, and the blood vessel size $500 \mu \mathrm{m}$ in diameter. Lower dermal blood content led to higher laser-induced epidermal peak temperature. At the laser pulse duration of $1.5 \mathrm{~ms}$, the laser-induced epidermal peak temperature increased from 130 to $156{ }^{\circ} \mathrm{C}$ when the dermal blood content decreased from $12 \%$ to $0.2 \%$. When 100 ms pulse duration was applied, the peak temperatures were 24 and $28.5^{\circ} \mathrm{C}$, respectively.

Accordingly, the threshold incident dosage for epidermal damage $D_{\text {th }}$ increased with increasing dermal blood content (Fig. 8b). At $1.5 \mathrm{~ms}$ pulse duration, $D_{\text {th }}$ increased from 54 to $65 \mathrm{~J} / \mathrm{cm}^{2}$ (increased by $20.3 \%$ ) when the dermal blood content increased from $0.2 \%$ to $12 \%$. When the pulse duration was $100 \mathrm{~ms}$, the threshold incident dosages were 238 and $280 \mathrm{~J} / \mathrm{cm}^{2}$ (increased by $17.6 \%$ ) for $0.2 \%$ and $12 \%$ dermal blood content, respectively.

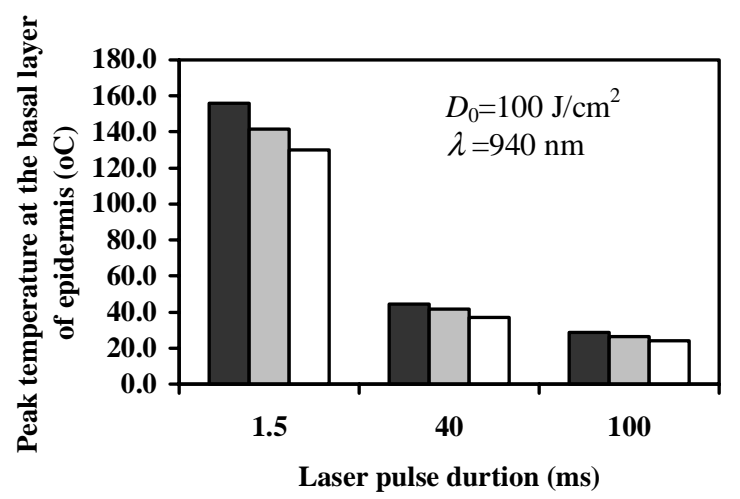

(a)

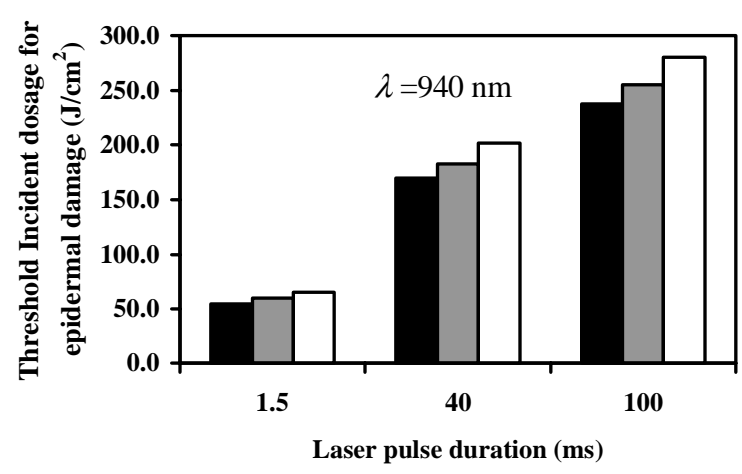

(b)

Figure 8: Effect of dermal blood content on (a): the laser-induced temperature at the basal layer of epidermis (incident dosage $D_{0}=100 \mathrm{~J} / \mathrm{cm}^{2}$ ) and (b): the threshold incident dosage for epidermal damage. Dermal blood content:

$0.2 \% \square 3 \% \square 12 \%$.

\subsection{Effect of dermal blood vessel size}

Simulation results showed that when the dermal blood content is constant, the effect of blood vessel size on the epidermal peak temperature and accordingly the threshold incident dosage for epidermal damage is minimum compared to that of dermal blood content (Fig. 9). For the example of $1.5 \mathrm{~ms}$ pulse duration, the threshold incident dosage increased from 59.6 to $61.5 \mathrm{~J} / \mathrm{cm}^{2}$ (increased only by $3.2 \%$ ) when the dermal blood size increased from 50 to $500 \mu \mathrm{m}$ (Fig. 9b). 


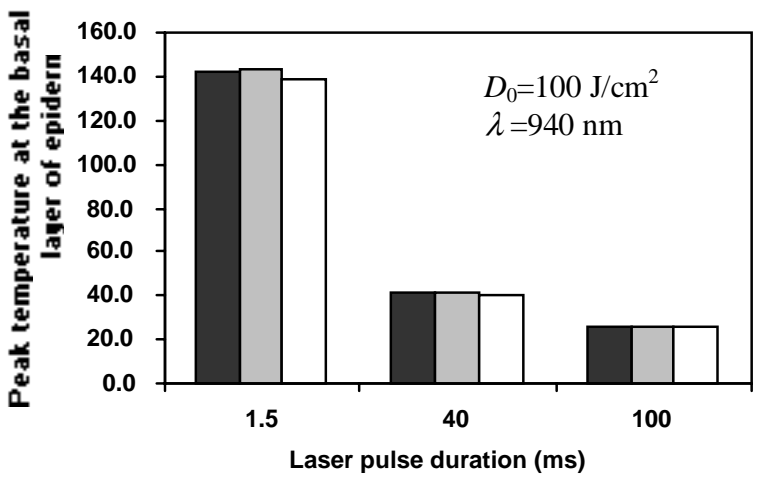

(a)

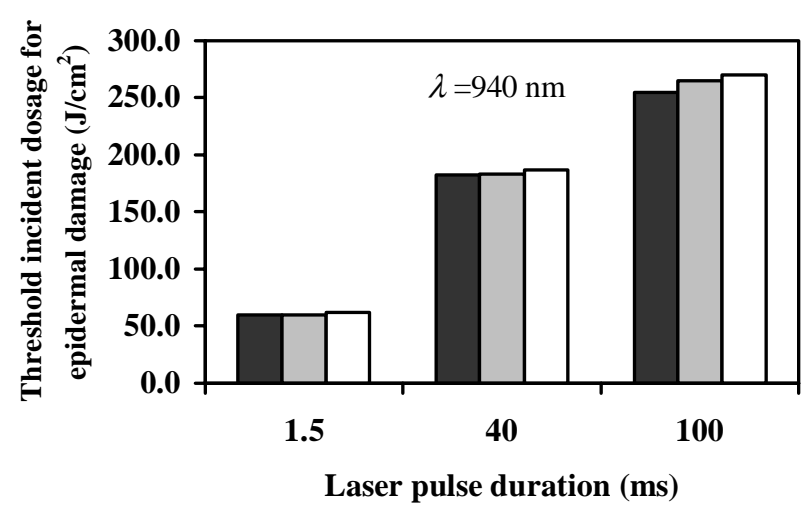

(b)

Figure 9: Effect of dermal blood vessel size on (a): the laser-induced temperature at the basal layer of epidermis (incident dosage

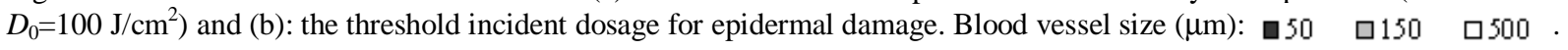

\section{DISCUSSION}

Results of this theoretical study indicated that optical selectivity could still be achieved at $940 \mathrm{~nm}$ wavelength. The absorption coefficient in blood at $940 \mathrm{~nm}$ is about 25 timers higher than that in dermis (Table 1). Unlike the pronounced gradient of light energy absorption in large-sized blood vessel at 585 and $595 \mathrm{~nm}$ wavelengths, the light energy distribution at $940 \mathrm{~nm}$ is approximately uniform within blood vessels (Fig. 3). This will give rise to more uniform heating of the blood vessel, and subsequently be beneficial to the photocoagulation of the entire blood vessel. The result also explains why pulsed dye lasers are inefficient in treating large-sized ectatic blood vessels. Most of the energy of pulsed dye laser irradiation, especially at $585 \mathrm{~nm}$ wavelength, is absorbed by very superficial layer of the blood vessel. Thus, the light penetration depth in blood is very limited, and subsequently, non-uniform heating of the blood vessel is induced.

$595 \mathrm{~nm}$ wavelength is now widely used in clinical settings instead of $585 \mathrm{~nm}$ with the intention to increase the light penetration depth in large-sized blood vessels or blood vessels extending deeply into dermis. As the light absorption by blood at $595 \mathrm{~nm}$ decreases by a factor of 5 comparing with $585 \mathrm{~nm}^{22}$, higher incident dosage is required to generate sufficient heat within blood vessels for coagulation. However, the light absorption by epidermal melanin at $595 \mathrm{~nm}$ is almost identical to that at $585 \mathrm{~nm}$, limiting the usage of high incident dosage and resulting in a poor treatment efficacy in moderately to heavily pigmented skin patients. A comprehensive comparison of the treatment efficacies for large-sized blood vessels between 595 and $940 \mathrm{~nm}$ wavelengths was carried out in the present study.

For lightly pigmented skin, in which epidermal melanin plays a less critical role, $940 \mathrm{~nm}$ wavelength shows the advantage over $595 \mathrm{~nm}$ in the photocoagulation depth in larger-sized blood vessels (Fig. 4). For moderately to heavily pigmented skin, $595 \mathrm{~nm}$ wavelength is constrained by the epidermal light absorption for using sufficient incident dosage to coagulate the blood vessel, even in conjunction with long cryogen spurt. In contrast, when long laser pulse duration (e.g. $200 \mathrm{~ms}$ ) and long cryogen spurt duration (e.g. $200 \mathrm{~ms}$ ) are applied, $940 \mathrm{~nm}$ even shows good efficacy in treating large-sized blood vessels in heavily pigmented skin (Fig. 7).

Dermal blood content has a considerable effect on the laser-induced peak temperature at the basal layer of epidermis. Lower dermal blood content leads to less light absorption by dermal blood and subsequently more back scattering from the dermis to the epidermis, resulting in higher laser-induced peak temperature in the basal layer, and accordingly, lower threshold incident dosage for epidermal damage. The laser-induced epidermal peak temperature is predicted to be minimally dependent on the size of dermal blood vessels. 
In summary, this theoretical investigation predicted that near-infrared wavelength $940 \mathrm{~nm}$ is promising in treating cutaneous hyper-vascular malformation patients with large-sized ectatic blood vessels and moderately to heavily pigmented skin types. Future experimental studies are needed to verify the results of the present study.

\section{CONCULSIONS}

This theoretical investigation indicated that laser irradiation using $940 \mathrm{~nm}$ wavelength is superior to $595 \mathrm{~nm}$ for the treatment of cutaneous hyper-vascular malformation patients with large-sized blood vessels and moderately to heavily pigmented skin types. Using long laser pulse duration and long cryogen spray duration, $940 \mathrm{~nm}$ wavelength is predicted to be efficient in treating dark skin patients. Dermal blood content has a considerable effect on the laser-induced peak temperature at the basal layer of epidermis, while the effect of blood vessel size is minimum when the dermal blood content is constant.

\section{ACKNOWLEDGEMENTS}

This study was supported in part by grants from the Institute of Arthritis and Musculoskeletal and Skin Disease (IR01AR47996) at the National Institutes of Health and Texas Higher Education Coordinating Board. We thank Dr. James W. Tunnell from G.R. Harrison Spectroscopy Laboratory at Massachusetts Institute of Technology for his fruitful discussions.

\section{REFERENCES}

1. B. Perez, M. Nunez, P. Bioxeda, A. Harto, A. Ledo, "Progressive ascending telangiectasia treated with $585 \mathrm{~nm}$ flashlamppumped pulsed dye laser," Lasers Surg. Med., 21, 413-416, 1997.

2. Y. Namba, O. Mae, M. Ao, "The treatment of port wine stains with a dye laser: a study of 644 patients, "Scand. J. Plast. Reconstr. Hand. Surg., 35, 197-202, 2001.

3. H. Wang, J. Wang, H. Jin, S. Wen, G. Jiang, "Flashlamp-pumped pulsed dye laser in treatment of port wine stains, " Chin. Med. Sci. J., 16, 56-58, 2001.

4. C. M. Nguyen, J. J. Yohn, C. Huff, W. L. Weston, J. G. Morelli, "Facial port wine stains in childhood: prediction of the rate of improvement as a function of the age of the patient, size and location of the port wine stain and the number of treatments with the pulsed dye (585 nm) laser, " Br. J. Dermatol., 138, 821-825, 1998.

5. W. S. Ho, H. H. Chan, S. Y. Ying, P. C. Chan, "Laser treatment of congenital facial port-wine stains: long-term efficacy and complication in Chinese patients", Lasers Surg. Med., 30, 44-47, 2002.

6. S.Hohenleutner, E. Badur-Ganter, M. Landthaler, U. Hohenleutner, "Long-term results in the treatment of childhood hemangioma with the flashlamp-pumped pulsed dye laser: An evaluation of 617 cases," Lasers Surg. Med., 28, 273277, 2001.

7. S. W. Lanigan, "Port-wine stains unresponsive to pulsed dye laser: explanations and solutions, " Br. J. Dermatol., 139, 173-177, 1998.

8. R. Ashinoff, R.G. Geronemus, "Treatment of a port wine stain in a black patient with pulsed dye laser," J. Dermatol Surg Oncol. 18: 147-148, 1992.

9. S. L. Jacques, "Skin Optics," http://omlc.ogi.edu/news/jan98/skinoptics.html.

10. S. Wray, M. Cope, D.T. Delpy, J. S. Wyatt, E. Reynold, "Characterization of the near infrared absorption spectra of cytochrome aa3 and haemoglobin for non-invasive monitoring of cerebral oxygenation, "Biochimica et Biophsica Acta, 933, 184-192, 1988.

11. A. Kienle, R. Hibst, "A new optimal wavelength for port wine stain?, " Phys. Med. Biol., 40, 1559-1576, 1995.

12. A. Roggan, K. Dorschel, O. Minet, D. Wolff, G. Muller, "The optical properties of biological properties in the near infrared wavelength range-review and measurements, " In: G. Muller, A. Roggan, editors, Laser-induced interstitial thermotherapy, SPIE Press, Bellingham, WA, 10-44, 1995.

13. A. Roggan, M. Friebel, K. Dorschel, A. Hahn, G. Muller, "Optical properties of circulating human blood in the wavelength range 400-2500 nm, " J. Biomed. Opt., 4, 36-46, 1999.

14. R. Graaff, A. C. M. Dassel, M. H. Koelink, F. F. M. de Mul, J. G. Aarnoudse, W. G. Zijlstra, "Optical properties of human dermis in vitro and in vivo, " Appl. Opt., 32, 435-447, 1993. 
15. L. Wang, S. L. Jacques, L. Zheng, "MCML-Monte Carlo modeling of light transport in muti-layered tissues, " Comput. Methods Programs Biomed., 47, 131-146, 1995.

16. J. W. Tunnell, L. V. Wang, B. Anvari, "Optimum pulse duration and radiant exposure for vascular laser therapy of dark port-wine skin: a theoretical study, " App. Opt., 42, 1367-1378, 2003.

17. F. A. Duck, Phsical properties of tissue, Academic press, London, 1990.

18. R. Agah, J. A. Pearch, A. J. Welch, M. Motamedi, "Rate process model for arterial tissue thermal damage: implications on vessel photocoagulation, " Lasers Surg. Med., 15, 176-184, 1994.

19. J. A. Weaver, A. M. Stoll, "Mathematical model of skin exposed to thermal radiation, " Aerosp. Med., 40, 24-30, 1969.

20. T. B. Fitzpatric, "The validity and practicality of sun-reactive skin types I through VI," Arch. Dermatol., 124, 869871,1988 .

21. J. W. Tunnell, D. W. Chang, C. Johnston, J. H. Torres, C. W. Patrick, Jr, M. J. Miller, S. L. Thomsen, B. Anvari, "Effects of Cryogen Spray Cooling and High Radiant Exposures on Selective Vascular Injury During Laser Irradiation of Human Skin, " Arch. Dermatol., 139, 743-750, 2003.

22. M. J. C. Van Gemert, A. J. Welch, J. W. Pickering, O. T. Tan, Laser treatment of port wine stains, In: A. J. Welch, M. J. C. van Gemert, editors, Optical-thermal response of laser-irradiated tissue, Plenum Press, New York, 789830, 1995. 